Original Article

\title{
Serum Magnesium and 25-Hydroxy Cholecalciferol in Premenstrual Syndrome during Luteal Phase
}

\author{
Sadia Tabassum Abbasi, Palwasha Abbasi, Ahmed Hussain Suhag, Mumtaz Ali Qureshi
}

\begin{abstract}
BACKGROUND: Premenstrual syndrome (PMS) is a recurrent cyclic disorder of cyclical changes in the sexual hormones. It is characterized by emotional, mental and physical symptoms, however pathophysiology is largely unknown. Treatment with drugs like antidepressants, oral contraceptives, GRH agonist has been tried. Recently it has been shown that the levels of 25-hydroxyvitamin $D_{3}$ and electrolytes such as magnesium have much importance in controlling the symptoms of PMS.

OBJECTIVE: To determine serum magnesium and 25-hydroxy cholecalciferol $\left(25-\mathrm{OH}-\mathrm{D}_{3}\right)$ in Premenstrual syndrome (PMS) during luteal phase.

METHODOLOGY: This comparative study was conducted at the Department of Gynecology and Obstetrics, Isra University Hospital during June-December 2013. Unmarried female ( $n=85)$ aged 18-28 years were selected through non-probability purposive sampling and divided into controls and those having premenstrual syndrome (PMS). 25-hydroxy cholecalciferol $\left(25-\mathrm{OH}-\mathrm{D}_{3}\right)$ was estimated by ARCHITECT I 1000 system and serum magnesium by DiaSys Merck system. Data was analyzed on SPSS version 21.0. Significant $p$-value was taken at $\leq 0.05$.

RESULTS: Vitamin 25-OH-D $-\mathrm{D}_{3}$ was found very low (14.88 \pm SD2.39) in cases of PMS, as compared to control (26.20 \pm SD4.30) and difference was statistically significant $(p=0.0001)$. Level of Vitamin $25-\mathrm{OH}-\mathrm{D}_{3}$ as low as $8 \mathrm{ng} / \mathrm{dl}$ was noted in PMS cases. Serum Mg++ was significantly differs between PMS cases and controls $1.72 \pm 0.31$ vs. $1.84 \pm 0.12 \mathrm{ng} / \mathrm{dl}(p=0.02)$. Vitamin $25-\mathrm{OH}-\mathrm{D}_{3}$ showed positive correlation with serum Mg++ levels $(r=0.24, p=0.02)$.

CONCLUSION: Serum magnesium and 25-hydroxychlecalciferol are low with positive correlation in female having premenstrual syndrome.
\end{abstract}

KEY WORDS: Magnesium, 25-hydroxychlecalciferol, Premenstrual syndrome.

This article may be cited as: Abbasi ST, Abbasi P, Suhag AH, Qureshi MA. Serum Magnesium and 25-Hydroxy Cholecalciferol in Premenstrual Syndrome during Luteal Phase. J Liaquat Uni Med Health Sci. 2017;16(04):209-12. doi: 10.22442/jlumhs.171640535

\section{INTRODUCTION}

Premenstrual syndrome (PMS) is characterized by a complex clinical syndrome characterized by the typical symptoms occurring during the luteal phase of menstrual cycle and at the end on menstrual cycle ${ }^{1}$. The PMS is a recurrent cyclic disorder of cyclical changes in the sexual hormones. PMS is characterized by emotional, mental and physical symptoms ${ }^{2}$. The pathophysiology of PMS in reproductive age group still remains unknown. Treatment with drugs like anti depressants, oral contraceptives and GRH agonist can reduce the symptoms of PMS but all of these drugs have their own side effects. Previous research suggests that the levels of 25-hydroxyvitamin $D_{3}$ and electrolytes such as magnesium have much importance in controlling the symptoms of $\mathrm{PMS}^{2}$. The patients suffering from PMS complains of subjective symptoms which may be non- specific such as the irritability, anxiety, tension, depression, tender feeling in breast, muscle and joint pain, mastalgia and cephalgia. This symptom complex of PMS disturbs daily life activities. PMS patients may experience suicidal thoughts, epilepsy like symptoms and breathing difficulty mimicking to the asthma; have all been reported ${ }^{3}$. Dietary intake of fortified dairy foods and cereals, fish, multivitamins and mineral supplements especially calcium contribute importantly to vitamin $D$ activity in elderly populations and those with low ambient sunlight exposure ${ }^{4}$. It is noted that women in the luteal phase having symptoms of PMS may be suffering from 25-hydroxyvitamin $D_{3}$ deficiency ${ }^{5}$. A good dietary source of vitamin $D_{3}$ may reduce the symptoms of $\mathrm{PMS}^{6}$. It is also reported that the level of vitamin $D_{3}$ is lower than normal in all subjects having PMS during their menstrual cycle. The possible cause may be the increased conversion of 25 $-\mathrm{OH}$ vitamin $\mathrm{D}_{3}$ into $1,25-\mathrm{OH}$ vitamin $\mathrm{D} 3$ during the luteal phase of their menstrual cycle which in turn increases the consumption of vitamin $D_{3}$ causing its low level in the body ${ }^{6}$. Magnesium $\left(\mathrm{Mg}^{++}\right)$deficiency is considered as an etiological factor of PMS. Altered serum magnesium $(\mathrm{Mg})$ levels have been associated 
with several neuropsychiatric symptoms. More common disorders are mood and physical one like, headache, chronic pain, epilepsy ${ }^{7,8}$. The women with PMS may have magnesium deficiency in plasma ${ }^{9}$, red blood cell (RBC) and mononuclear blood cell (MBC) ${ }^{10}$ compared to women without PMS. Different studies suggest that the oral Mg supplementation in women with PMS is more effective in raising the mood ${ }^{11}$ and fluid retention symptoms ${ }^{12}$. However, the differences in levels of $\mathrm{Mg}$ between women with PMS and control subject or progress in symptoms of PMS in response to the administration of $\mathrm{Mg}$ supplements is still not clear $^{13}$. The rationale of present study was conducted to evaluate serum magnesium and 25-hydroxy cholecalciferol (Vitamin $D_{3}$ ) in Premenstrual syndrome during Luteal Phase and if proved then a modifiable cause may be eliminated by the physicians.

\section{METHODOLOGY}

The ethical approval for the present study was taken from ethics committee of the institute. This comparative study was conducted at the Department of Gynecology and Obstetrics, Isra University, Hyderabad from July-December 2013. As per inclusion criteria 85 unmarried female aged between 18-28 years having regular menstrual cycle, not taking any drug were included in study through non-probability purposive sampling technique. Those having PMS were considered as study group $(n=43)$ and those with no history of PMS $(n=42)$ served as control. Married female with concomitant systemic disease, multi-vitamin and drug users were excluded. The nature of the study was explained and informed written consent was taken from each participants. Five $\mathrm{ml}$ of fasting venous blood sample was drawn from ante-cubital vein during luteal phase. The blood was centrifuged at 4000rpm for ten minutes and serum obtained was frozen at $-20^{\circ} \mathrm{C}$. The serum was used for estimation of magnesium and 25-hydroxyvitamin $\mathrm{D}_{3}$ levels. From blood sera, 25-hydroxyvitamin $\mathrm{D}_{3}$ was measured by ARCHITECT I 1000 system and serum magnesium by DiaSys Merck system. The data recorded on a pre-structured proforma entered and analyzed on SPSS version 21.0 (IBM Incorporation USA). The categorical and continuous variables were analyzed by chi-square test and student's t-test respectively. The findings presented as mean $\pm S . D$ and frequency (\%) respectively. Pearson's correlation was used for determining the association of 25-hydroxyvitamin $D_{3}$ and serum magnesium. The significant $p$-value was taken at $\leq 0.05 \quad(95 \%$ confidence interval).

RESULTS

Mean $\pm S . D$ age of controls and premenstrual syndrome (PMS) cases was $22.6 \pm 3.2$ and $21.6 \pm 3.9$ years respectively ranging from $18-28$ years $(p=0.91)$. The premenstrual subjects shows a significantly low vitamin $D_{3}$ levels compared to controls $14.88 \pm 2.39$ $\mathrm{ng} / \mathrm{dl}$ vs. $26.20 \pm 4.30$ respectively and the difference was statistically significant $(p=0.0001)$ as shown in Table I. Serum vitamin $D_{3}$ levels as low as $8 \mathrm{ng} / \mathrm{dl}$ was noted in premenstrual syndrome.

The serum magnesium levels between groups were analyzed using student's t-test. The mean \pm S.D of serum magnesium levels in control and those with PMS was $1.84 \pm 0.12$ and $1.72 \pm 0.31 \mathrm{mg} / \mathrm{dl}$ respectively. Significant statistical difference was observed for serum magnesium level between groups $(p=0.0001)$ as shown in table I. Positive correlation coefficient was observed between serum vitamin $D_{3}$ and magnesium levels $(r=0.24, p=0.02)$ as shown in graph I.

\section{TABLE I. SERUM MAGNESIUM AND 25-HYDROXY CHOLECALCIFEROL IN PREMENSTRUAL SYNDROME SUBJECT $(n=85)$}

\begin{tabular}{|l|c|c|c|}
\hline & $\begin{array}{c}\text { Group I. } \\
\text { Control } \\
(\mathbf{n = 4 2})\end{array}$ & $\begin{array}{c}\text { Group II. } \\
\text { Cases } \\
(\mathbf{n}=\mathbf{4 3})\end{array}$ & P-value \\
\hline $\begin{array}{l}\text { 25-hydroxyvitamin } \\
D_{3}(\mathrm{ng} / \mathrm{dl})\end{array}$ & $26.20 \pm 4.30$ & $14.88 \pm 2.39$ & 0.0001 \\
\hline $\begin{array}{l}\text { Serum } \\
\text { Magnesium (mg/dl) }\end{array}$ & $1.84 \pm 0.12$ & $1.72 \pm 0.31$ & 0.020 \\
\hline
\end{tabular}

GRAPH I: SCATTER PLOT: POSITIVE CORRELATION COEFFICIENT WAS OBSERVED BETWEEN SERUM VITAMIN D3 AND MAGNESIUM LEVELS $(r=0.244, p=0.022)$

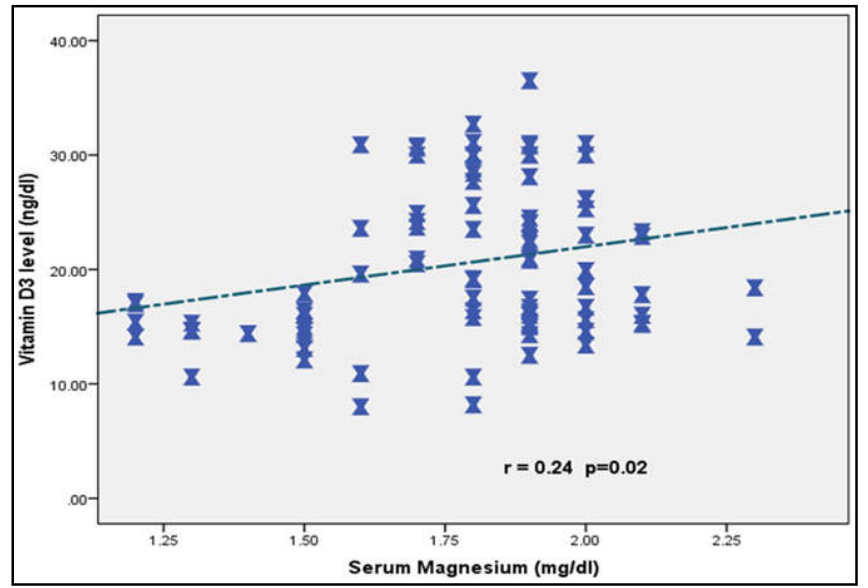

\section{DISCUSSION}

The present is the first research reporting on the serum magnesium and 25-hydroxy cholecalciferol in Premenstrual syndrome (PMS) during Luteal Phase 
from our institute. Statistical analysis shows low serum magnesium and 25-hydroxy cholecalciferol in PMS during Luteal Phase. These findings are consistent with previous studies ${ }^{5-7}$. Previous studies ${ }^{6-7}$ reported the serum 25-hydroxy cholecalciferol fluctuate during the Luteal phase, the finding supports our similar observation. Previous reviews ${ }^{5-7}$ reported low serum magnesium and 25-hydroxyvitamin D3 levels which is supporting the present findings. A previous analysis ${ }^{8}$ reported the ovarian sex hormones induce enzymes which degrade the 25-hydroxyvitamin $D_{3}$. They analyzed the effects of estradiol hormone on the 1-a-hydroxylase and 24-hydroxylase action in the liver and found increased catalytic activity of these enzymes stimulated by estradiol, this decreases the serum 25-hydroxyvitamin $D_{3}$. Hence our findings are supported and consistent with above study. The findings of present research of serum 25hydroxyvitamin $D_{3}$ has been demonstrated by previous studies $^{5-7}$, but we are the first to analyze and reporting on these parameters from our institute. Our findings are worth and supported by previous studies as cited ${ }^{5-}$ 7. It is suggested that the ovarian hormones peak during Luteal phase which degrade the 25hydroxyvitamin $D_{3}$ and subsequently lead to its low levels in the serum. Low 25-hydroxyvitamin $D_{3}$ may cause low serum $\mathrm{Mg}++$ which is observed in the present study. These findings suggest the ovarian hormones disturb the serum $\mathrm{Mg}++$ and 25hydroxyvitamin $D_{3}$ metabolism in cyclical fashion, and these might aggravate the symptoms of PMS. A previous study ${ }^{9}$ reported elevated serum parathyroid hormone (PTH) in healthy female suffering from PMS. This previous study proved a progressive increase in PTH and low serum 25-hydroxyvitamin $\mathrm{D}_{3}$ through the ovarian cycle. This previous study reported a $30-35 \%$ rise in serum PTH during earlier follicular and late luteal phase with a simultaneous decrease in serum ionized $\mathrm{Mg}++$ and 25-hydroxyvitamin $\mathrm{D}_{3}$. Evidence based findings of present study, supported by above studies suggest the low serum $\mathrm{Mg}++$ and 25-hydroxyvitamin $D_{3}$ during luteal phase in those suffering from the PMS. A previous study ${ }^{15}$ estimated plasma concentrations of Magnesium, Manganese, Selenium and Zinc in menstruating female and reported low levels of all during ovulatory phase. But serum $\mathrm{Mg++}$ and Selenium were raised during Lutéal Phase. The findings of above study are inconsistent to present and previous studies ${ }^{12-14}$. Reason of contradictory findings could be different study population, geographical areas, sample size and methods of metal estimation. Another previous case control study ${ }^{16}$ analyzed serum $\mathrm{Mg}++$ and 25-hydroxyvitamin $D_{3}$ after supplements in a cohort of 1057 female. They reported the symptoms of PMS were low compared to controls. Our findings are consistent to above and others ${ }^{12-21}$. Still another previous study ${ }^{3}$ reported $\mathrm{Mg}$ therapy alleviated premenstrual dysphoric symptoms. Our finidgns are also consistent with a previous controlled clinical trial ${ }^{18}$ which offered $\mathrm{Mg++}$ and Pyridoxine therapy to PMS patients. Supplements of $250 \mathrm{mg} \mathrm{Mg++}$ were proved effective in relieving the symptoms of PMS in particular the anxiety, craving and depression. Present study findings also support the positive relationship of low serum magnesium with symptoms of PMS. In light of literature review and evidence based findings of present study, it is suggested the serum $\mathrm{Mg++}$ and 25 -hydroxy vitamin $D_{3}$ levels are low during luteal phase of menstrual cycle due to cyclical changes in the release of hormones of hypothalamo-pituitary-ovarian axis.

\section{CONCLUSION}

The present study reports low serum magnesium and 25-hydroxychlecalciferol in the subjects suffering from premenstrual syndrome Supplementation with vitamin $D_{3}$ and magnesium may help alleviate the symptoms of premenstrual syndrome.

\section{REFERENCES}

1. Saeedian Kia A, Amani R, Cheraghian B. The Association between the Risk of Premenstrual Syndrome and Vitamin D, Calcium, and Magnesium Status among University Students: A Case Control Study. Health Promot Perspect. 2015; 5(3): 225-30. doi: 10.15171/hpp.2015.027

2. Matsumoto $\mathrm{T}$, Asakura $\mathrm{H}$, Hayashi $\mathrm{T}$. Biopsychosocial aspects of premenstrual syndrome and premenstrual dysphoric disorder. Gynecol Endocrinol. 2013; 29(1):67-73. doi: 10.3109/09513590.2012.705383.

3. Verma RK, Chellappan DK, Pandey AK. Review on treatment of premenstrual syndrome: from conventional to alternative approach. J Basic Clin Physiol Pharmacol. 2014; 25(4):319-27. doi: https://doi.org/10.1515/jbcpp-2013-0072.

4. Marjoribanks J, Brown J, O'Brien PM, Wyatt K. Selective serotonin reuptake inhibitors for premenstrual syndrome. Cochrane Database Syst Rev. 2013; 6:CD001396. doi: 10.1002/14651858.

5. Darabi F, Rasaie N, Jafarirad S. The relationship between premenstrual syndrome and food patterns in university student girls. JJHR. 2014; 5 (6):e26656. doi: 10.5812/jjhr.26656

6. Taghizadeh Z, Shirmohammadi M, Feizi A, Arbabi $M$. The effect of cognitive behavioural psycho-education on premenstrual syndrome and related symptoms. J Psychiatr Ment Health Nurs 2013; 20(8):705-13. DOI: 10.1111/j.1365- 
2850.2012.01965.x

7. Sen AP, Gulati A. Use of Magnesium in traumatic brain injury. Neurotherapeutics 2010; 7(1):91-9. doi: 10.1016/j.nurt.2009.10.014.

8. Zafari M, Aghamohammady A. Comparison of the effect of Vit E, Vit B6, Calcium and omega-3 on the treatment of premenstrual syndrome: a clinical randomized trial. Annual Research and Review in Biology. 2014; 4(7):1141-49.

9. Bertone-Johnson ER, Hankinson SE, Forger NG, Powers SI, Willett WC, Johnson SR, et al. Plasma 25-hydroxyvitamin $\mathrm{D}$ and risk of premenstrual syndrome in a prospective cohort study. BMC Women's Health. 2014; 14:56.

10. Chocano-Bedoya PO, Manson JE, Hankinson SE, Johnson SR, Chasan-Taber L, Ronnenberg AG, et al. Intake of selected minerals and risk of premenstrual syndrome. Am J Epidemiol. 2013; 177(10):1118-27. doi: 10.1093/aje/kws363.

11. Bakhshani N, Hasanzadeh Z. Relationship of premenstrual syndrome and nutritional style. Medical $\mathrm{J}$ of Mashhad University of Medical Sciences. 2012; 55:151-157.

12. Skowrońska $P$, Pastuszek E, Kuczyński W, Jaszczoł M, Kuć $P$, Jakiel $G$, et al. The role of vitamin $D$ in reproductive dysfunction in women a systematic review. Ann Agric Environ Med. 2016; 23(4): 671-676. doi: 10.5604/12321966. 1226865.

13. Miyashita M, Koga K, Izumi G, Sue F, Makabe T, Taguchi A, et al. Effects of 1,25-Dihydroxy Vitamin D 3 on Endometriosis. J Clin Endocrinol Metab. 2016; 101(6): 2371-9. doi: 10.1210/jc.2016-1515

14. Harris HR, Chavarro JE, Malspeis S, Willett WC, Missmer SA. Dairyfood, calcium, magnesium, and vitamin D intake and endometriosis: A prospective cohort study. Am J Epidemiol. 2013; 177(5): 420-30. doi: 10.1093/aje/kws247

15. Shahrokhi SZ, Ghaffari F, Kazerouni F. Role of vitamin $\mathrm{D}$ in female Reproduction. Clin Chim Acta. 2016; 455: 33-8. doi: 10.1016/j.cca.2015.12.040.

16. Ghalwa NA, El-Qidra R, Wahedy M. Impact of calcium and magnesium dietary changes on women pain and discomfort from premenstrual syndrome at the Faculty of Pharmacy- Gaza Strip. World J Pharm Pharmaceut Sci. 2014; 3(2):981-1005.

17. Najam R, Bano N, Ahmed SP. The therapeutic role of magnesium in different depressive syndromes of female patients. Pak J Pharmacol. 2010; 27(2):1-8.

18. Ebrahimi E, Motlagh SK, Nemati S, Tavakoli Z. Effects of magnesium and vitamin B6 on the severity of premenstrual syndrome symptoms. J Caring Sci. 2012; 1(4): 183-9. doi: 10.5681/ jcs.2012.026

19. Fathizadeh $\mathrm{H}$, Ebrahimi $\mathrm{E}$, Valliani $\mathrm{M}$, Tavakoli $\mathrm{N}$, Yar MH. Evaluating the effect of magnesium and magnesium plus vitamin B6 supplement on the severity of premenstrual syndrome. Iran J Nurs Midwifery Res. 2010; 15 (Suppl 1) : 401-5.

20. Shu-Hui Cheng, Chi-Chen Shih, Yen-Kuang Yang, Kow-Tong Chen, Yun-Hsuan Chang, Yi-Ching Yang. Factors associated with premenstrual syndrome - A survey of new female university students. KJMS. 2013; 29(2):100-5.

21. Seedhom AE, Mohammed ES, Mahfouz EM. Life Style Factors Associated with Premenstrual Syndrome among El-Minia University Students, Egypt. ISRN Public Health. 2013; 2013:1-6. doi: $10.1155 / 2013 / 617123$.
AUTHOR AFFILIATION:

Dr. Sadia Tabassum Abbasi

(Corresponding Author)

Assistant Professor, Département of Biochemistry

Isra University Hyderabad, Sindh-Pakistan.

E mail: Giggly786@gmail.com

Dr. Palwasha Abbasi

Assistant Professor, Département of Pharmacology

Isra University Hyderabad, Sindh-Pakistan.
Dr. Ahmed Hussain Suhag

Assistant Professor, Department of Physiology Liaquat University of Medical \& Health Sciences Jamshoro, Sindh-Pakistan.

\section{Dr. Mumtaz Ali Qureshi}

Professor, Department of Biochemistry Isra University Hyderabad, Sindh-Pakistan. 